\title{
THE RENCONTRES FOCUS: OUTCOMES OF A LEARNING AND STUDY SKILLS BASED PROGRAM FOR UNDERGRADUATE STUDENTS WITH ATTENTION DEFICIT HYPERACTIVITY DISORDER (ADHD)
}

\author{
Rachel Paquette, France Landry, Georgette Goupil, \& Julien Dalpé \\ Department of psychology, Université du Québec à Montréal (Canada)
}

\begin{abstract}
Undergraduate studies require good organizational, planning and time management skills. As several studies showed, students with Attention Deficit Hyperactivity Disorder (ADHD) have weaker learning and study strategies than students without ADHD (Gormley, DuPaul, Weyandt, \& Anastopoulos, 2016; Reaser, Prevatt, Petscher, \& Proctor, 2007). Some universities have therefore implemented support measures for those students. In Quebec (Canada), Landry (2012) developed the Rencontres FOCUS, which aim to enhance learning and study skills. This study evaluated the effects of the Rencontres FOCUS on the learning and study strategies of thirteen undergraduate students with ADHD (six men and seven women, $M_{\text {age }}=29.2$ years). The French version of the Learning and Study Strategy Inventory (LASSI, Weinstein and Palmer, 2002) was used to evaluate participants' study skills. Dependent $t$-tests compared the pre and post-intervention scores. Participants significantly improve on Anxiety, Concentration, Selecting Main Ideas and Test Strategy subscales with a moderate to large size effect. However, results indicate that the participants remain below the $50^{\text {th }}$ percentile of the LASSI. This suggests that, despite their progress, those students have to continue to improve their study skills. The results also reveal that the Rencontres FOCUS seems relevant for the development of study strategies for students with ADHD.
\end{abstract}

Keywords: ADHD, university, study skills, group intervention.

\section{Introduction}

The prevalence of Attention deficit hyperactivity disorder (ADHD) in higher education students is estimated between 3 and 7 \% (Emmers, Jansen, Petry, van der Oord, \& Baeyens, 2017). ADHD is associated with long-term impairment in educational attainment, occupational status and social relationship (Barkley, Murphy, \& Fischer, 2008). Students with ADHD are more likely to present lower grade point average, to drop out of their program or to complete their program later than their peers without ADHD (Gormley, DuPaul, Weyandt, \& Anastopoulos, 2016). Barkley's theoretical framework (1997) places the self-regulatory deficits at the center of many problems students with ADHD tend to present, such as difficulties in concentration, information processing, organization, time management, motivation, etc.

Although several programs have been developed specifically for enhancing learning and study skills, none of them were adapted in French. To answer the increasing demands in Université du Québec à Montréal's student services, Landry (2012) developed the Rencontres FOCUS, a six weeks program aiming to enhance study skills of students with ADHD using cognitive and behavioral theories. Since 2012, seven cohorts participated in the program. In order to evaluate the students' appreciation of the program, Dalpé, Landry and Goupil (2019) conducted a qualitative data analysis and found that many participants mentioned they felt they improved their study skills. In continuation with their work, this study aims to empirically assess the effects of the Rencontres FOCUS program on learning and study skills of participants using a pre and post-intervention research design.

\section{Method}

\subsection{Participants}

Participants were 13 French-speaking Canadian undergraduate students with ADHD (six men and seven women, $M_{\text {age }}=29.2$ years). Data were collected on three consecutive cohorts of the Rencontres FOCUS between January 2017 and May 2018. 


\subsection{Instrument and Procedure}

Intervention. An educational psychologist and a doctoral student in psychology conducted the two-hour group sessions in a university setting. They presented the content mainly using a question-and-answer format to stimulate active student participation in the group discussion. Lecture format and explicit teaching were sometimes used when illustrating certain strategies. Table 1 details the session-by-session topics for the Rencontres FOCUS.

Table 1. Session-by-session topics of the Rencontres FOCUS.

\begin{tabular}{|c|c|c|c|c|c|c|}
\hline Sessions & $\begin{array}{l}\text { 1. ADHD and } \\
\text { educational } \\
\text { project }\end{array}$ & $\begin{array}{c}\text { 2. Time } \\
\text { management } \\
\text { and activity } \\
\text { planning }\end{array}$ & $\begin{array}{l}\text { 3. Attention and } \\
\text { material } \\
\text { organization }\end{array}$ & $\begin{array}{l}\text { 4. Reading and } \\
\text { writing }\end{array}$ & $\begin{array}{c}\text { 5. Stress } \\
\text { management }\end{array}$ & $\begin{array}{l}\text { 6. Motivation } \\
\text { and transition to } \\
\text { future } \\
\text { workplace }\end{array}$ \\
\hline
\end{tabular}

Pre- and post-intervention. Participants completed the French version of the Learning and Study Strategy Inventory (LASSI, Weinstein \& Palmer, 2002) at the first and last sessions. The 80-item test contains 10 eight-item scales. Students respond to items using a five-point Likert scale, ranging from "not at all typical of me" to "very much typical of me". For each subscale, the scores obtained are presented in the form of raw scores and percentiles.

\subsection{Data analysis}

Statistical analyzes used Excel to perform means, standard deviations, dependent $t$-tests between pre and post-intervention and Cohen's $d$. When significant differences on $t$-tests were found, the effect size was calculated by Cohen's $d$, where a $d$ of $.2, .5, .8$ respectively indicate a small, moderate, and large effect. Since the goal of this study was to see if there were any effects on the learning strategies, the analysis took into account percentile and raw data, so we could detect any variations between pre and post-intervention. The results of these analyzes are presented in Table 2.

\section{Results}

Results shown in Table 2 reveal improvement in four out of ten study strategies measured by the LASSI. Analyzes show a significant improvement in the raw scores of the following subscales: anxiety, $t(12)=-3.25, p=0.004$ and a moderate to large size effect. Analyzes also indicate a significant improvement in concentration $t(12)=-3.42, p=0.025$; main idea selection strategies $t(12)=-1.96$, $p=0.037$ and test strategies $t(12)=-1.80, p=0.049$ The effect size for the last three subscales shows a moderate range. Although we can observe that the percentile for all of the subscales improve, nine of the ten subscales remain below the $50^{\text {th }}$ percentile.

Table 2. LASSI pre and post-intervention raw and percentile scores of students with ADHD $(N=13)$.

\begin{tabular}{|c|c|c|c|c|c|c|c|c|}
\hline \multirow{2}{*}{ Subscales } & \multicolumn{2}{|c|}{ Raw Scores } & \multirow[b]{2}{*}{$t$} & \multirow[b]{2}{*}{$d$} & \multicolumn{2}{|c|}{ Percentile } & \multirow[b]{2}{*}{$t$} & \multirow[b]{2}{*}{$d$} \\
\hline & $\frac{\text { Pre-int. }}{M(S D)}$ & $\frac{\text { Post-int. }}{M(S D)}$ & & & $\frac{\text { Pre-int. }}{M(S D)}$ & $\frac{\text { Post-int. }}{M(S D)}$ & & \\
\hline Anxiety & $20.9(7.3)$ & $24.3(7.9)$ & $-3.25 * *$ & 0.66 & $29.8(29.0)$ & $44.8(32.2)$ & $-2.95 * *$ & 0.69 \\
\hline Attitude & $30.0(2.9)$ & $30.3(3.0)$ & -0.39 & & $19.7(17.6)$ & $23.2(19.0)$ & -0.72 & \\
\hline Concentration & $20.1(5.7)$ & $22.8(7.8)$ & $-3.42 * *$ & 0.40 & $18.8(17.3)$ & $32.9(29.7)$ & $-3.28 * *$ & 0.55 \\
\hline Self-testing & $19.9(3.9)$ & $20.9(6.2)$ & -0.90 & & $23.1(21.5)$ & $32.1(29.9)$ & -1.57 & \\
\hline Selecting Main Idea & $22.1(8.1)$ & $24.4(6.8)$ & $-1.96^{*}$ & 0.44 & $28.5(28.8)$ & $32.5(28.8)$ & -0.85 & \\
\hline Study Aids & $24.0(4.4)$ & $25.2(6.5)$ & -1.17 & & $41.2(26.8)$ & $49.9(30.7)$ & -1.65 & \\
\hline Time Management & $20.2(4.9)$ & $21.5(7.3)$ & -1.02 & & $20.9(20.4)$ & $28.2(30.8)$ & -1.55 & \\
\hline Test Strategies & $25.8(5.9)$ & $27.7(5.9)$ & $-1.80^{*}$ & 0.48 & $33.7(24.8)$ & $43.2(29.5)$ & -1.55 & \\
\hline
\end{tabular}




\section{Discussion}

The goal of this study was to measure and compare the learning and study skills of undergraduate students using the LASSI in a pre- and post-intervention research design. For the raw data comparison, the results suggest that undergraduate students with ADHD significantly improved their study skills on four out of ten subscales: Anxiety, Concentration, Selecting Main Idea and Test Strategies. Also, even if there were no significant differences, we can observe that participants improved on the six other subscales, showing a great potential for this novel and francophone program. Those results are consistent with research concerning group-based and peer-based intervention for students with ADHD (Anastopoulos \& King, 2015; Prevatt \& Yelland, 2013).

Although results showed that participants were able to enhance their study skills, we can notice that they remain under the $50^{\text {th }}$ percentile in most subscales. Thus, they remain in the "at risk" category, the last of the three LASSI ranking categories. This suggests that, despite their progress, additional initiatives are required to improve their study skills. Considering the prevalence of students with ADHD, support programs in universities could include individualized support from professionals, follow up sessions or peer-coaching.

\section{Limitations and future directions}

This study has some limitations. First, due to sample and institutional constraints, we were not able to assemble a control group to assess the program's direct effect on the participants. Second, the small sample size may have been insufficient to note significant differences between pre- and post-intervention. Future research should focus on exploring the psychosocial factors implicated in the success of the program such as the level of implication of individuals, the group cohesion, the role of the group counselors, etc. More studies on college and university initiatives like the Rencontres FOCUS could contribute to bring to light new and useful ways of helping students with ADHD.

\section{References}

Anastopoulos, A. D., \& King, K. A. (2015). A cognitive-behavior therapy and mentoring program for college students with ADHD. Cognitive and Behavioral Practice, 22(2), 141-151.

Barkley, R. A. (1997). Behavioral inhibition, sustained attention, and executive functions: Constructing a unifying theory of ADHD. Psychological Bulletin, 121(1), 65-94.

Barkley, R. A., Murphy, K. R., \& Fischer, M. (2008). ADHD in adults: What the science says. New York, NY: Guilford Press.

Dalpé, J., Landry, F., \& Goupil, G. (2019). Étude exploratoire sur la validité sociale des Rencontres FOCUS pour les étudiants universitaires ayant un TDAH [Exploratory study on social validity of the Rencontre FOCUS for university student with ADHD] (accepted for publication). Science et comportement.

Emmers, E., Jansen, D., Petry, K., van der Oord, S., \& Baeyens, D. (2017). Functioning and participation of students with ADHD in higher education according to the ICF framework. Journal of Further and Higher Education, 41, 435-447.

Gormley, M. J., DuPaul, G. J., Weyandt, L. L., \& Anastopoulos, A. D. (2016). First-year GPA and academic service use among college students with and without ADHD. Journal of Attention Disorders, 20(1), 1-14.

Landry, F. (2012). Programme de renforcement des stratégies d'étude pour les étudiants universitaires ayant un TDAH. [Study strategies enhancing program for university student with ADHD] (Unpublished doctoral dissertation). Université du Québec à Montréal: Montréal, Canada.

Prevatt, F., \& Yelland, S. (2015). An empirical evaluation of ADHD coaching in college students. Journal of attention disorders, 19(8), 666-677.

Reaser, A., Prevatt, F., Petscher, Y., \& Proctor, B. (2007). The learning and study strategies of college students with ADHD. Psychology in the Schools, 44(6), 627-638.

Weinstein, C. E., \& Palmer, D. R. (2002). LASSI user's manual: For those administering the Learning and Study Strategies Inventory. Clearwater, Floride: H \& H Publishing. 